\title{
CLAUDE BRUNIER COULIN, JEAN-FRANÇOIS PETIT (EDS.). LE STATUT ACTUEL DE LA MÉTAPHYSIQUE. ACTES DU COLLOQUE DES 6-8 JUILLET 2018. ORIZONS : PARIS, 2019. 420p.
}

La Académie Catholique du Val de Seine publica su tercer coloquio Internacional que, en su versión de 2018, trata sobre el estado actual de la metafísica, bajo la dirección de los profesores Claude Brunier-Coulin y Jean François Petit. La que fuese alguna vez"reina de las ciencias", vive hoy una agonía interminable que se ha prolongado a lo largo del siglo XX, desacreditación principalmente heredada de la crítica heideggeriana y la filosofía analítica. Su rechazo, superación y deconstrucción -por autores como Wittgenstein, Derrida, Habermas, Rorty, o Putnam- han llevado a la metafísica a una muerte lenta y han conducido a la modernidad a proclamarse antimetafísica o post-metafísica. Desde este complejo punto de partida y con el fin de comprender esta -supuesta-lenta agonía, la publicación reúne los artículos correspondientes a 17 conferencias ${ }^{1}$, además de una adhesión con breves conclusiones.

El libro comienza con la conferencia inaugural pronunciada por Geneviève Hébert. Centrada en el estado "problemático" de la metafísica, la autora realiza un repaso tanto histórico como filológico sobre la materia en cuestión y destaca las dificultades que impone su análisis desde aquellas que

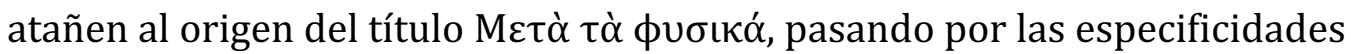
y omisiones de la exposición aristotélica, hasta la crisis moderna de su herencia. En respuesta al motivo inicial de la exposición, la autora declara

${ }^{1}$ Le statut problématique de la 'métaphysique' (Conférence inaugural), Geneviève Hebert (p. 13-27); Réponse à la conférence inaugural, Michel Boyancé (p. 29-35); Penser selon la conscience, Claude Brunier-Coulin (p. 39-65); La métaphysique entre déclin et renaissance, Michel Faye (p. 67-88) ; De l'incompréhensibilité du monde, André Sarrazin (p. 89-163); En quel sens faut-il dépasser la métaphysique?, Ivan Neykov (p. 165-80); La science Contemporaine débouche sur de Nouveaux Problèmes Métaphysiques, Viviana Yacuzzi Polisena (p. 18192); Métaphysique et mystique 'L'ailleurs' de la métaphysique, Jean-François Petit (p. 193209); La métaphysique comme condition a priori de l'esthétique : une réflexion autour de La Croisée du visible de Jean-Luc Marion, Aurore Boni (p. 211-26); La philosophie de la nature et la possibilité d'une métaphysique contemporaine, Emmanuel Brochier (p. 227-45); Les raisons d'une dépréciation de la métaphysique quand on a 17 ans : question d'âge ou question d'héritage ?, Violaine de Lartigue (p.247-66); Le mythe de la caverne, début de la métaphysique? Les sources héraclitéenne et parménidienne, William Néria (p.267-90); Herméneutique et métaphysique, Vincent Laquais (p. 291-309); La perspective métaphysique, Martine Chifflot-Comazzi (p. 311-27); Apport des métaphysiques rebelles pour une réflexion actuelle,Yves Meessen (p. 329-40); La nouvelle métaphysique thomiste, Daniel Torrijos-Castrillejo (p. 341-65); La métaphysique et l'éthique à la rescousse d'une nouvelle réflexion de l'être, Mona Gradescu (p. 367-93). 
que la metafísica hoy en día, a pesar de los problemas que implican su estudio y análisis, se ha abierto caminos dentro de la filosofía moderna:

Ya no se trata de la metafísica en un sentido neo-escolástico. Se trata de encontrar el camino que nos conduce "más-allá" del triste positivismo de las leyes de la naturaleza, allí donde se abre el camino de la ética para evitar nuestra condición errante, de la experiencia estética para conocer la alegría, y así muchas otras vías que abren al sentido, la esperanza y lo infinito. (p 26) ${ }^{2}$

En respuesta a esta conferencia inaugural, Michel Boyancé -Director del Institut de Philosophie Comparée de Paris -, una vez que expone brevemente sobre la "rehabilitación" de la metafísica a través de la ética, da como ejemplo lo observado en uno de los diversos proyectos asesorados por la institución que encabeza, en este caso, la colaboración con equipos médicos dedicados a los cuidados paliativos de enfermos terminales. A partir de la premisa sobre la búsqueda del sentido del ser en este particular contexto, argumenta cómo la experiencia ética se encuentra indisolublemente ligada a la experiencia metafísica. Sobre esto, el autor observa:

Aquello a lo cual nos referimos de la persona en modo 'abstracto', también es aplicado a los pacientes. De cierta manera lidiamos concretamente con que su existencia es del todo tributaria de su esencia, que ésta existe en el ser que existe, el ente, y así da sentido y principio a la decisión que tomamos. (p. 33) ${ }^{3}$

Ambas exposiciones, encargadas de abrir el debate, marcan el tono de las conferencias que siguen, donde primará -a diferencia de lo sugerido en la introducción- una visión inesperadamente optimista e integradora sobre la viva presencia de la metafísica en distintos campos de la filosofía actual. Así destaca el trabajo de Michel Faye, quien, bajo la consideración de la actualidad de la metafísica como un estudio que oscila entre declive y renacimiento, sostiene que su supervivencia pasa por superar el reduccionismo fenomenológico de su análisis. El objeto de estudio específico de la metafísica sería entonces el ser, pero entendido como el milieu de la consciencia, el intermediario o el espejo a través del cual el espíritu adquiere la certeza de la impotencia de lo finito para satisfacer su exigencia fundamental, que sobrepasa el mundo de los fenómenos a través de los

2 "Il ne s'agit plus de métaphysique au sens de la néo-scholastique. Il s'agit de trouver le chemin qui nous conduit «au-delà » de la triste positivité des lois de la nature, là où s'ouvre le chemin de l'éthique pour éviter l'errance, le chemin de l'expérience esthétique pour connaître la joie, et bien d'autres chemins encore qui ouvrent sur le sens, l'espérance, et l'infini“'Todas las citas son traducción propia.

3 “Ce que l'on dit 'abstraitement' de la personne, on le dit aussi [du patients]. D'une certaine manière, nous touchons donc concrètement que son existence est bien tributaire de son essence, que celle-ci existe dans l'être existant, l'étant, et elle donne sens et principe à la décision que nous prenons" 
cuales el ser se refleja. Con estas consideraciones se alinean los trabajos de Claude Brunier-Coulin y Jean-François Petit, quienes por su parte también defienden una reconducción de los medios de análisis ontológicos del ser.

De gran relevancia son además los trabajos que abordan -en la dirección propuesta por Boyancé al comienzo- la problematización de la metafísica desde la ética. Con el fin de abrir un horizonte de sentido al cuestionamiento del ser, Ivan Neykov sostiene que toda tentativa de interrogante metafísica, y por ende la pregunta sobre su superación y estado actual, debe estar ligada a la relación del ser en cuanto tal desde su experiencia ética.Mona Gradescu, por su parte, adhiere a esta postura, si bien desde la perspectiva trascendentalista del bien.

En la línea de este coloquio que intenta aunar variadas perspectivas y ejes de investigación, expone la especialista en estética Aurore Boni. La autora, que funda su análisis en la obra de Jean-Luc Marion "La croisée du visible" ${ }^{4}$ considera la estética como una forma particular de metafísica, como un despliegue en acto al momento de la experiencia estética del arte y, por lo tanto, como un ámbito efectivo que da cuenta de la actualidad de la metafísica. Asimismo participa del debate la hermenéutica, ponencia a cargo de Vincent Laquais, quien a partir de los trabajos de Wilhelm Dilthey, Jean Grondin y H. G. Gadamer, argumenta la condición de la metafísica como un esfuerzo inevitable de comprensión $\mathrm{y}$, por lo tanto, vigilante del pensamiento humano. Así, la metafísica se perfila como una herramienta íntimamente ligada al ejercicio de la hermenéutica -entendida como la teoría de las operaciones de la comprensión que implican la interpretaciónpara comprender el conjunto de la realidad, sus razones y principios. El conjunto se transforma en un esfuerzo de voluntad, necesario para comprender la trascendencia más allá de la inmanencia de un sentido que, articulado en el lenguaje, no es simple creación del espíritu sino -en palabras de Gadamer - el sentido de las cosas mismas.

Esta multiplicidad de perspectivas se observa también desde el ámbito de las ciencias aplicadas, en los artículos de André Sarrazin yViviana Yacuzzi Polisena. La filósofa argentina Yacuzzi adopta los enfoques analíticos de la filosofía de la ciencia y la física cuántica para mostrar la necesidad de integrar, a los avances científicos actuales, un debate metafísico que logre reflexionar sobre la manera en que los descubrimientos de la ciencia contemporánea actualizan los problemas metafísicos:

\footnotetext{
${ }^{4}$ Hay versión española: Marion, Jean-Luc. 2006. El cruce de lo visible. Ellago.
} 
Mi objetivo es (...) revelar que en el centro de toda teoría científica hay una metafísica que sostiene la estructura constitutiva de toda ciencia, y que esta es la marca de su nuevo status contemporáneo. (p. 182)

La intervención de Violaine de Lartigue -doctoranda del Institut Catholique de Toulouse- actúa como testimonio clave del carácter pluralista de este coloquio. Lartigue, desde su experiencia como profesora de secundaria, expone las miradas y posiciones de sus estudiantes frente a la metafísica y los cuestionamientos existenciales a los que conduce su reflexión. Concluye que, lejos de la supuesta inutilidad, ausencia y caducidad atribuida a la metafísica, esta sigue siendo un lugar fecundo para las interrogantes sobre el ser y la existencia, un debate vivo que, incluso a los 17 años, es asociado a una "necesidad inagotable" e inherente a nuestra naturaleza humana y racional.

Digamos, por último, que la introducción de Claude Brunier-Coulin al inicio de la obra, deja en claro la radicalidad del rechazo de la metafísica a lo largo del último siglo, ya que expone el problema ontológico que se impone al análisis del ser. En base a esto, la respuesta a la interrogación que plantea el coloquio sobre el estado actual de la metafísica pareciera estar determinada a confirmar su propia determinación. Sin embargo, las respuestas expresadas en la variada colección de artículos presentados evidencian optimismo acerca de la importancia, actualidad y futuro de la metafísica, no solo en diversos ámbitos del análisis filosófico -estética, teología, ética, hermenéutica-, sino también en el campo de la ciencia, la física cuántica, la psicología e incluso la pedagogía. La diversidad de las posiciones, interpretación de textos y temas de la metafísica analizados marcan el éxito de los objetivos de este coloquio. Aunque del conjunto de contribuciones no es posible llegar a una respuesta conclusiva que determine cuál es exactamente el estado actual de la metafísica, sí se puede inferir el propósito por reavivar un debate supuestamente anquilosado, de un estudio cuyo objeto se considera casi superado por la filosofía del último siglo. Si bien queda demostrado que hoy en día la metafísica no se caracteriza necesariamente por una coherencia total ni un movimiento organizado, sí se constatan permanencias, rupturas y giros desde diversas líneas de estudio. Esto da cuenta de una presencia actual y fecunda, no solo analizable desde un enfoque exclusivamente teórico, sino también en una orientación aplicada a la experiencia humana concreta, lo cual amplía las perspectivas de debate y la posibilidad última de una "reactivación" de los estudios actuales sobre metafísica. En efecto, es un campo que la actividad

5 “Mon but est (...) de révéler qu'au fond de toute théorie scientifique il y a une métaphysique qui soutient la structure constitutive de toute science et que cela est la marque de son nouveau statut contemporain." 
académica francesa no ha cesado de promover ${ }^{6}$, como resume para finalizar Jean-François Petit:

No cabe ninguna duda sobre el valor permanente [de la metafísica]. Nuestra propensión a cuestionar e interrogar la ausencia de evidencias, continuará siendo por mucho tiempo el "mejor aguijón" de la metafísica, bajo la condición de que esta sirva con prioridad a la fundación más que a la instrumentalización. (p. 399) ${ }^{7}$

Carmen Luz Olmos de Aguilera M.

Université Jean Moulin - Lyon 3

Institut de Recherches Philosophiques de Lyon IRPHIL, Francia. carmen.olmos-de-aguilera@univ-lyon3.fr

${ }^{6}$ Pinchard, Bruno. et Zarka, Yves.-C. (dir.). 2005. Y-a-t-il une histoire de la métaphysique ? Paris : PUF ; Harder, Y.-J. 2006. Histoire et métaphysique. Paris : Éditions de la Transparence ; Aubenque, Pierre. 2009. Faut-il déconstruire la métaphysique ? Paris : PUF.

7 “(...) Le valeur permanente [de la métaphysique] ne fera ici aucun doute. Notre propension au questionnement, à interroger notamment les inévidences, continuera pour longtemps à être le «meilleur aiguillon » de la métaphysique, à condition que celle-ci soit plus de la fondation que de l'instrumentalisation" 